\title{
Isomeric Recognition by Ion/Molecule Reactions: The Ionized Phenol- Cyclohexadienone Case
}

\author{
Laetitia Trupia, ${ }^{a}$ Noémie Dechamps, ${ }^{\text {a }}$ Robert Flammang, ${ }^{\text {a }}$ \\ Guy Bouchoux, ${ }^{\mathrm{b}}$ Minh Tho Nguyen, ${ }^{\mathrm{c}}$ and Pascal Gerbaux ${ }^{\mathrm{a}}$ \\ a Organic Chemistry Laboratory, Organic Mass Spectrometry Center, University of Mons-Hainaut, Mons, Belgium \\ b Laboratoire des Mécanismes Réactionnels, UMR CNRS 7651, Département de Chimie, Ecole Polytechnique, \\ Palaiseau Cedex, France \\ ${ }^{c}$ Department of Chemistry and Mathematical Modelling \& Computational Science Centre, University of \\ Leuven, Leuven, Belgium
}

The isomerization process between ionized phenol and ionized cyclohexadienone is studied by performing ion/molecule reactions with several alkyl nitrites in a hexapole collision cell inserted in a six-sector mass spectrometer. The distinction between both isomeric species is readily achieved on the basis of the completely different reactivity patterns observed for them in subsequent reactions. When reacting with alkyl nitrite, ionized phenol undergoes two competitive reactions corresponding to the formal radical substitution of the hydroxylic hydrogen atom by respectively (i) the nitrosyl radical $(\mathrm{m} / \mathrm{z} 123)$ and (ii) an alkoxyl radical $(\mathrm{m} / \mathrm{z}$ 138 if alkyl = ethyl). Both reactions were theoretically demonstrated by density functional theory calculations [B3LYP/6-311++G(d,p) + ZPE] to involve hydrogen-bridged radical cations as key intermediates. The ion/molecule reaction products detected starting from ionized cyclohexadienone as the mass-selected ions arise from ${ }^{\circ} \mathrm{OAlkyl}{ }^{\bullet} \mathrm{OH}$, and $\mathrm{NO}_{2}{ }^{\bullet}$ radical additions. The occurrence of a spontaneous ring-opening of cyclohexadienone radical ion into a distonic species is suggested to account for the observed ion/molecule reaction products. We also demonstrated that ionized cyclohexadienone is partly isomerized during a proton-transfer catalysis process into ionized phenol inside the Hcell with ethyl nitrite as the base. The molecular ions of phenol generated in such conditions consecutively undergo reactions producing $\mathrm{m} / \mathrm{z} 123$ and 138 radical cations. The proposed mechanism is supported by results of quantum chemical calculations. (J Am Soc Mass Spectrom 2008, 19, 126-137) () 2008 American Society for Mass Spectrometry

$\mathrm{K}$ eto-enol isomerization of gaseous molecules and ions has extensively been studied and reported [1]. It is now well established that, in both condensed and gas phases, neutral carbonyl compounds are usually more stable than their enol tautomers. Exceptions to this rough rule are nevertheless observed when the carbon-carbon double bond of the enol becomes conjugated with another functional group such as a second carbonyl group or included in an aromatic moiety (see following text). The remarkable feature when dealing with the ionized species is that they show a reversed stability order. Indeed, as a rule, enol ions are always by far the most stable structures within a set of isomeric radical cations. As a consequence, enol ions often appear as reaction intermediates or as the ultimate ionic product of a fragmentation process. The higher stability of ionized enols with regard to the corresponding ionized carbonyl com-

Address reprint requests to Dr. Pascal Gerbaux, University of MonsHainaut, Organic Mass Spectrometry Center, Organic Chemistry Laboratory, 19 Avenue Maistriau, B-7000 Mons, Belgium. E-mail: pascal.gerbaux@ umh.ac.be pounds is explained on the basis of the large difference between the ionization energies (IEs) of the neutral molecules, the IE of the neutral enol being always by far lower than the IE of the corresponding carbonyl compound [2]. The usual considerable difference between the IEs being much larger than the energy difference between both neutral molecules explains the inversion in the stability order after ionization [2].

The thermochemical stability of an ionized enol is also associated with a large kinetic stability. In other words, enol ions are generally protected against dissociation or isomerization by significant energy barriers [3]. Consequently, ionized enols are predisposed model ions for fundamental studies in mass spectrometry such as associative ion/molecule investigations [4]. In this context, we recently demonstrated that the isomeric distinction between ionized enols and ionized carbonyl compounds can be readily achieved in the gas phase of a mass spectrometer by analysis of their chemical reactivity toward neutral alkyl nitrite [5]. Indeed, whereas the protonation and charge exchange reactions are the dominating pro- 


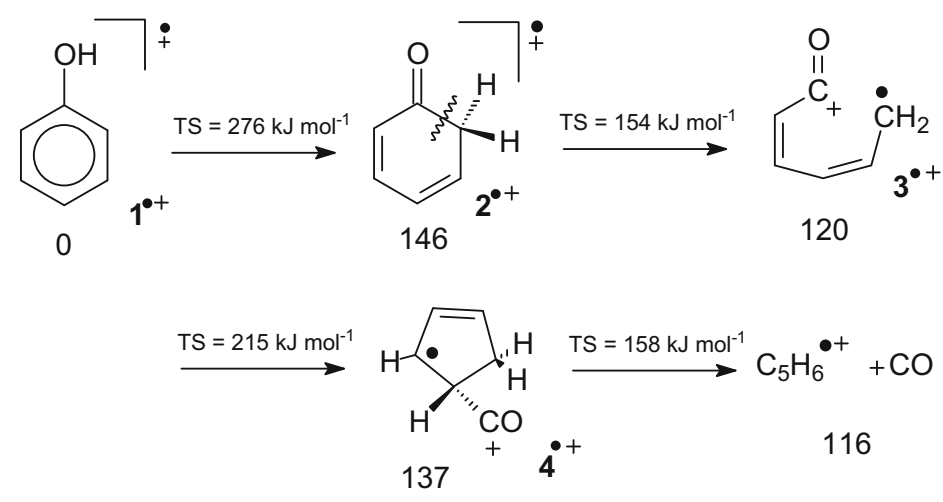

Scheme 1. Metastable decarbonylation of ionized phenol [8].

cesses in most cases, the isomeric enol-carbonyl recognition is straightforward on the basis of a lone reaction: the substitution of the hydroxylic hydrogen atom by nitric oxide in the enol ions [5]. In that paper, we reported the reactivities of quite simple ionized enols and carbonyl compounds such as (for the carbonyl species) ionized acetaldehyde, acetone, acetic acid, acetamide, and acetophenone. These compounds share the property that, in the neutral state, the carbonyl isomer is more stable than the enol counterpart $[1-3,6]$.

In the present work, we seek to extend this investigation to the ionized phenol-cyclohexadienone case in which, whatever the charge state, the enol structurethe phenol structure (1)-is much more stable than the 2,4-cyclohexadienone isomer (2) (see Scheme 1 [1]). Although ionized phenol $\left(\mathbf{1}^{\bullet+}\right)$ and its cyclohexadienone isomer $\left(2^{\bullet+}\right)$ were already abundantly studied [7], we recently experimentally and theoretically reinvestigated the $\mathrm{C}_{6} \mathrm{H}_{6} \mathrm{O}^{\bullet+}$ system to, inter alia, shed more light on the energetics of the mechanism of decarbonylation, the least energy demanding dissociation of ionized phenol [8]. This reaction was shown to involve the intermediacy of ionized cyclohexadienone $\left(2^{\bullet+}\right)$ and two distonic ions $\left(3^{{ }^{+}}\right.$and $\left.4^{\bullet+}\right)$, as shown in Scheme $\mathbf{1}$ (values indicated below the formula correspond to relative energies in $\mathrm{kJ} \mathrm{mol}^{-1}$ ) [8]. The rate-determining step of the overall process corresponds to the enolketone isomerization $\mathbf{1}^{\boldsymbol{}+} \rightarrow \mathbf{2}^{\boldsymbol{\bullet}+}$ with an energy barrier of about $276 \mathrm{~kJ} \mathrm{~mol}^{-1}$ above ionized phenol. This was consecutively experimentally confirmed in a threshold collision-induced dissociation study carried out by Muntean and Armentrout [9].

This paper reports the results of an experimental and theoretical study of the bimolecular gas-phase chemistry between ionized phenol and/or ionized cyclohexadienone with neutral alkyl nitrites inside a modified six-sector instrument fitted with an rf-only hexapole collision cell as the reaction chamber. Structures of the ion/molecule reaction products as well as the reaction mechanisms were proposed on the basis of density functional theory (DFT) calculations using the hybrid B3LYP functional with the $6-311++G(d, p)$ basis set.

\section{Experimental}

\section{Methods}

The mass spectrometric experiments were performed on a large-scale tandem mass spectrometer (Waters AutoSpec $6 \mathrm{~F}$, Manchester, UK) having a $\mathrm{c}_{1} \mathrm{E}_{1} \mathrm{~B}_{1} \mathrm{C}_{2} \mathrm{E}_{2} \mathrm{C}_{3} \mathrm{C}_{4} \mathrm{E}_{3} \mathrm{~B}_{2} \mathrm{C}_{5} \mathrm{E}_{4}$ geometry, where $\mathrm{E}$ stands for electric sector, $\mathrm{B}$ for magnetic sector, and c for the collision cells [10]. Typical ion source conditions were $8 \mathrm{kV}$ accelerating voltage, $200 \mu \mathrm{A}$ trap current in the electron ionization mode, and $70 \mathrm{eV}$ ionizing electron kinetic energy. The solid samples were introduced with a direct insertion probe, whereas the liquid samples were injected into the ion source by a heated septum inlet $\left(160^{\circ} \mathrm{C}\right)$. This instrument has been recently modified with an rf-only hexapole collision cell (Hcell) between $E_{2}$ and $E_{3}$ as recently reported elsewhere [11]. This modification allows the study of associative ion/ molecule reactions of decelerated ions having about $5 \mathrm{eV}$ kinetic energy. Briefly, the experiments utilizing the Hcell consist of the selection of a beam of fast-moving ions (8 $\mathrm{keV}$ ) with the three first sectors and the deceleration of these ions to about $5 \mathrm{eV}$ before entering the hexapole cell to maximize the yields of the associative ion/molecule reactions between the ions and the neutral reagent (pressure measured inside the cell with a pirani gauge: $\sim 10^{-3}$ Torr). After reacceleration to $8 \mathrm{keV}$, all the ions generated in the hexapole cell are separated and mass-measured by scanning the field of the second magnet. The high-energy collisional activation (CA) spectra of mass-selected ion/ molecule reaction ionic products can be recorded by a linked scanning of the fields of the last three sectors (collision in $\mathrm{c}_{4}$ ) or by scanning the field of the last electric sector after mass selection by the second magnet and collision in the fifth $\left(c_{5}\right)$ collision cell.

All the compounds considered in this work were commercially available and were used without any further purification, except for ethyl nitrite [12](a), propyl nitrite [12](a) and 2,5-dioxo-bicyclo[2.2.2]octan7,8-dicarboxylic anhydride (DODA) [12](b), which were prepared according to procedures described in the literature. 

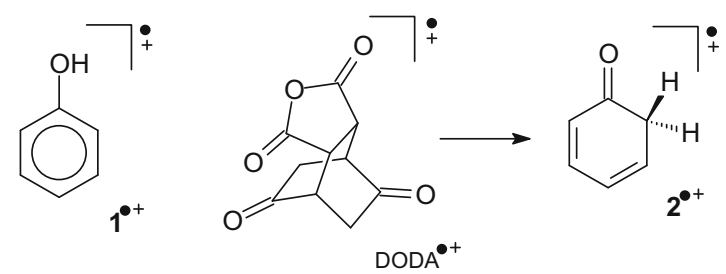

Scheme 2

\section{Calculations}

Quantum chemical calculations using DFT were performed using the GaussianW 98 suite of programs [13]. Geometries were optimized by using the hybrid B3LYP functional in conjunction with the polarized double- $\zeta$ plus diffuse functions $6-311++G(d, p)$ basis set. The spin-unrestricted (UHF, UB3LYP) method was used for open-shell systems. Spin contamination in the UB3LYP calculation was small as judged from the $\left\langle\mathrm{S}^{2}\right\rangle$ operator expectation values that ranged from 0.75 to 0.77 . The optimized structures were subsequently characterized by harmonic vibrational analyses as local minima (all frequencies real) at the same level. The B3LYP/6$311++\mathrm{G}(\mathrm{d}, \mathrm{p})$ frequencies were scaled by 0.98 to evaluate the zero-point vibrational contributions ( $\mathrm{ZPE})$ to the relative energies.

\section{Results and Discussion}

Ionized Phenol and Ionized Cyclohexadienone: GasPhase Preparation and CA Experiments

Ionized phenol $\left(\mathbf{1}^{\bullet+}\right)$ and ionized cyclohexadienone $\left(2^{\bullet+}\right)$ can be prepared in an EI source by, respectively, direct electron ionization of phenol and dissociative ionization of 2,5-dioxo-bicyclo[2.2.2]octan-7,8-dicarboxylic anhydride (DODA) (see Scheme 2).

The electron ionization spectrum of DODA (not shown) features a significant peak (50\% of the $\mathrm{m} / \mathrm{z} 110$ base peak) at $\mathrm{m} / \mathrm{z}$ 94, which may be ascribed to the formation of $\mathbf{2}^{\bullet+}$ by successive eliminations of carbon dioxide, carbon monoxide, and ketene. The literature reveals that CA spectra of ions $\mathbf{1}^{\mathbf{+}}$ and $\mathbf{2}^{\mathbf{* +}}$ can be compared to make a distinction between both species [7](d). However, only slightly different relative abundances of some fragment ions, mainly with respect to the $\mathrm{m} / \mathrm{z} 55$ signal, were noticed. The so-observed $\mathrm{m} / \mathrm{z} 55$ cations, identified as the aromatic hydroxycyclopropenyl cation, are significantly produced after collisional activation of ionized phenol-not ionized cyclohexadienone- only in the high kinetic energy regime $(8 \mathrm{keV})$. Consequently, it is interesting to find out structurally informative associative ion/molecule reactions for the ionized phenol-ionized cyclohexadienone case in the context of a low kinetic energy experimental setup.

The close similarity between both CA spectra can readily be explained on the basis of the potential energy surface connecting ion $\mathbf{1}^{\bullet+}$, ion $\mathbf{2}^{\bullet+}$, and their fragments [8]. Indeed, it was theoretically demonstrated (see
Scheme 1) that (i) decarbonylation represents the least energy requirement fragmentation of ion $\mathbf{1}^{\bullet+}$ and ion $2^{\mathbf{0}^{+}}$, (ii) that the loss of carbon monoxide from $\mathbf{1}^{\mathbf{*}^{+}}$ occurs by the intermediacy of $\mathbf{2}^{\circ+}$, and (iii) that the corresponding transition structure is lower in energy than the loss of hydrogen atom from $\mathbf{1}^{\bullet+}$ by no less than $100 \mathrm{~kJ} \mathrm{~mol}^{-1}$ [8]. In other words, post-collisional isomerization processes are likely to occur between activated $\mathbf{1}^{\bullet+}$ and $\mathbf{2}^{\cdot+}$. In such circumstances, it is often helpful to investigate bimolecular ion/molecule reactions undergone by the isomeric species toward a neutral target [14].

Recently, phenyl nitrite molecular ion was prepared by ion/molecule reaction in a gaseous mixture of phenol, methyl nitrite, and methanol under chemical ionization conditions (CI) [15]. Ion/molecule reactions were also conducted with mass-selected $\mathbf{1}^{\bullet+}$ ions that were allowed to react with gaseous tert-butyl nitrite. This reaction was also shown to produce ionized phenyl nitrite [15] and, consequently, mimics the wellknown condensed phase nitrosation of neutral alcohols under acidic conditions. Likely this peculiar reaction could allow a clear distinction between ions $\mathbf{1}^{\circ+}$ and $\mathbf{2}^{\bullet+}$ because ionized cyclohexadienone $\left(\mathbf{2}^{\bullet+}\right)$ is a priori not expected to react with an alkyl nitrite in a similar way.

\section{Associative Ion/Molecule Reactions between} Ionized Phenol $\mathbf{1}^{\bullet+}$ and Ethyl Nitrite: Overview of the Ion/Molecule Reaction Products

The interaction between mass-selected ionized phenol $\mathbf{1}^{\bullet+}(\mathrm{m} / \mathrm{z} 94)$, prepared by electron ionization of phenol, and neutral ethyl nitrite in the hexapole cell leads to the production of four major ionic species that are observed at $m / z$ 66, 93, 123, and 138 (see Figure 1); $m / z 66$ radical cations are already observed without any ethyl nitrite

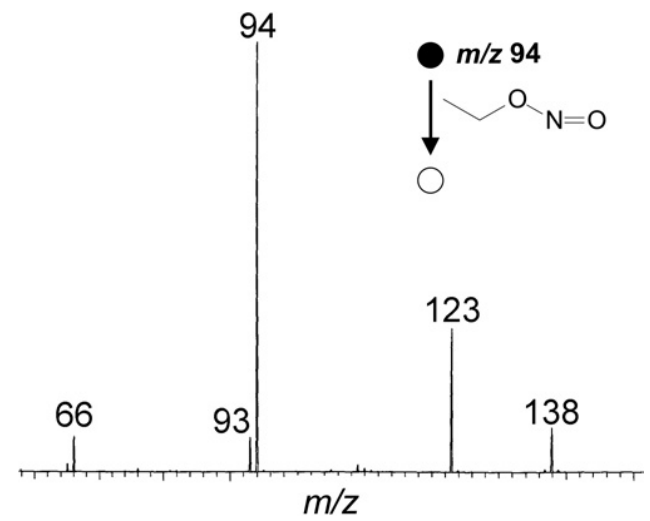

Figure 1. Associative ion/molecule reactions between ionized phenol $\mathbf{1}^{\bullet+}(\mathrm{m} / \mathrm{z}$ 94) and ethyl nitrite in the hexapole collision cell: mass spectrum of the reaction products (B scan). The terminology used to schematize the ion/molecule interactions is that introduced by Schwartz et al. [16]: a filled circle represents a fixed (or selected) mass; an open circle, a variable (or scanned) mass, whereas the neutral reagent that causes the mass transition is shown between the circles. 


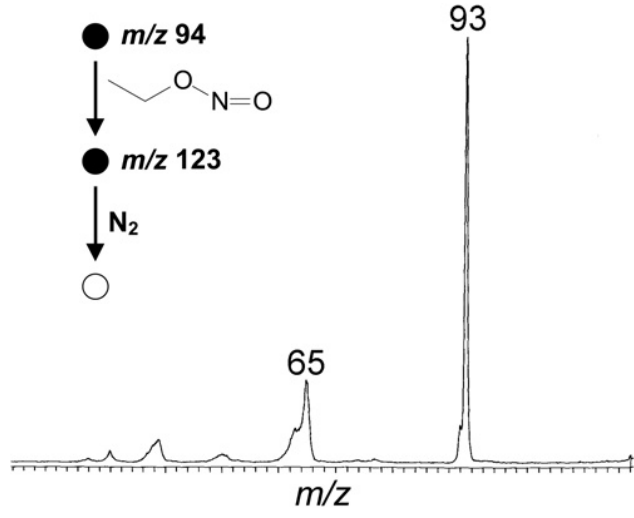

Figure 2. Associative ion/molecule reactions between ionized phenol $\mathbf{1}^{\bullet+}(\mathrm{m} / \mathrm{z}$ 94) and ethyl nitrite in the hexapole collision cell: CA spectra (8000 eV, $\mathrm{N}_{2}$ collision gas) of $\mathrm{m} / \mathrm{z} 123$ radical cations.

introduced in the hexapole cell. The corresponding ions, identified as the molecular ions of cyclopentadiene, consequently arise from the metastable decomposition, loss of carbon monoxide, from the massselected phenol ions. On the other hand, the three other ionic species, detected at $m / z$ 93, 123, and 138, require the presence of the neutral reagent in the Hcell and therefore originate from bimolecular processes.

The next paragraphs will summarize the experimental and theoretical data that allowed the structural characterization of the observed reaction products. Consecutively, on the basis of the so-determined structures together with the results obtained by DFT calculations, the reaction mechanisms leading to the ion/ molecule reaction products will be proposed.

\section{Associative Ion/Molecule Reactions between Ionized Phenol $\mathbf{1}^{\bullet+}$ and Ethyl Nitrite: Structural Characterization of $m / z 93$ and 123 Ions}

As explained earlier, phenyl nitrite molecular ion $\mathbf{1 A}^{\bullet+}$ is generated when reacting ionized phenol and alkyl nitrite either in the chemical ionization source [15] or in a quadrupole collision cell [15], respectively without and with mass selection of the reactive $m / z 94$ ions. The structure of the so-prepared radical cations $\mathbf{1 A}^{\bullet+}$ was already demonstrated by collisional activation experiments. The CA spectrum of $\mathbf{1 A}^{\bullet+}$ is distinctly different from the CA spectra of isomer ions such as nitrobenzene and nitrosophenol molecular ions. In the context of the present work, it is important to emphasize that the main collision-induced dissociation undergone by the $m / z 123$ radical cations (see Figure 2) affords $m / z 93$ ions by a loss of $30 \mathrm{Da}$ (nitric oxide). This is exactly what was observed for phenyl nitrite molecular ion $\mathbf{1 A}^{\bullet+}$ [15]. In other words, this major fragmentation reveals that (i) $\mathrm{m} / \mathrm{z} 123$ ions originating from the reaction between ionized phenol and ethyl nitrite possess structure $\mathbf{1 A}^{\bullet+}$ and (ii) the decomposition of internally excited $m / z 123$ ions, consecutively to their production, is certainly responsible for the formation of the phenoxy cations $\left(\mathbf{1 B}^{\mathbf{+}}\right)$, observed at $\mathrm{m} / \mathrm{z} 93$ in Figure 1 (see Scheme $\mathbf{3}$ ).

The interaction between $\mathbf{1}^{\bullet+}$ and neutral ethyl nitrite was then theoretically investigated at the B3LYP/6-311++G(d,p) level of theory, the potential energy diagram schematizing the ion/molecule reaction mechanism is presented in Figure 3 and discussed hereafter. First of all, starting from ionized phenol and ethyl nitrite, the bimolecular reactions leading to ionized phenyl nitrite $\mathbf{1 A}^{\bullet+}$ and consecutively to the phenoxy cation $\mathbf{1 B}^{+}$are calculated to be respectively thermoneutral and endothermic by 106 $\mathrm{kJ} \mathrm{mol}^{-1}$. At this point of the discussion, it is worth recalling that, in the gas phase, only the exothermic and the thermoneutral processes are allowed to occur if the reactants are in thermal equilibrium. Observation of the nitrosation reaction of ionized phenol is therefore totally in agreement with the theoretical data. At variance, the subsequent decomposition of ionized phenyl nitrite $\mathbf{1 A}^{\mathbf{}^{++}}$to afford the phenoxy cation $\mathbf{1 B}^{+}$could appear problematic. However, the experimental setup, described earlier in the experimental section, does not allow any thermalization step of the mass-selected ions before the reaction. Consequently, mass-selected ionized phenol could present some extent of internal energy at the moment of the reaction, especially because phenol molecular ions are prepared upon EI conditions. This excess of internal energy brought by the reactive ions could induce endothermic processes. The observation, among the ion/molecule reaction products, of the $\mathrm{m} / \mathrm{z}$ 66 radical cations coming from the metastable decomposition of ionized phenol fixes the extent of internal energy excess in the reactive ions to $276 \mathrm{~kJ} \mathrm{~mol}^{-1}$ that is the energy barrier on the way to the decarbonylation of ionized phenol [8] (see Scheme 1 and Figure 3). This threshold being by far higher than the energy required by the endothermic process clearly rationalizes the observation of the $\mathrm{m} / \mathrm{z} 93$ ions.

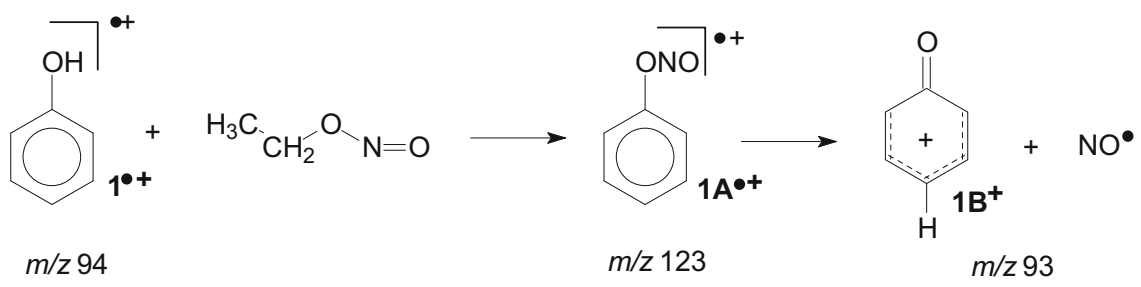

Scheme 3 


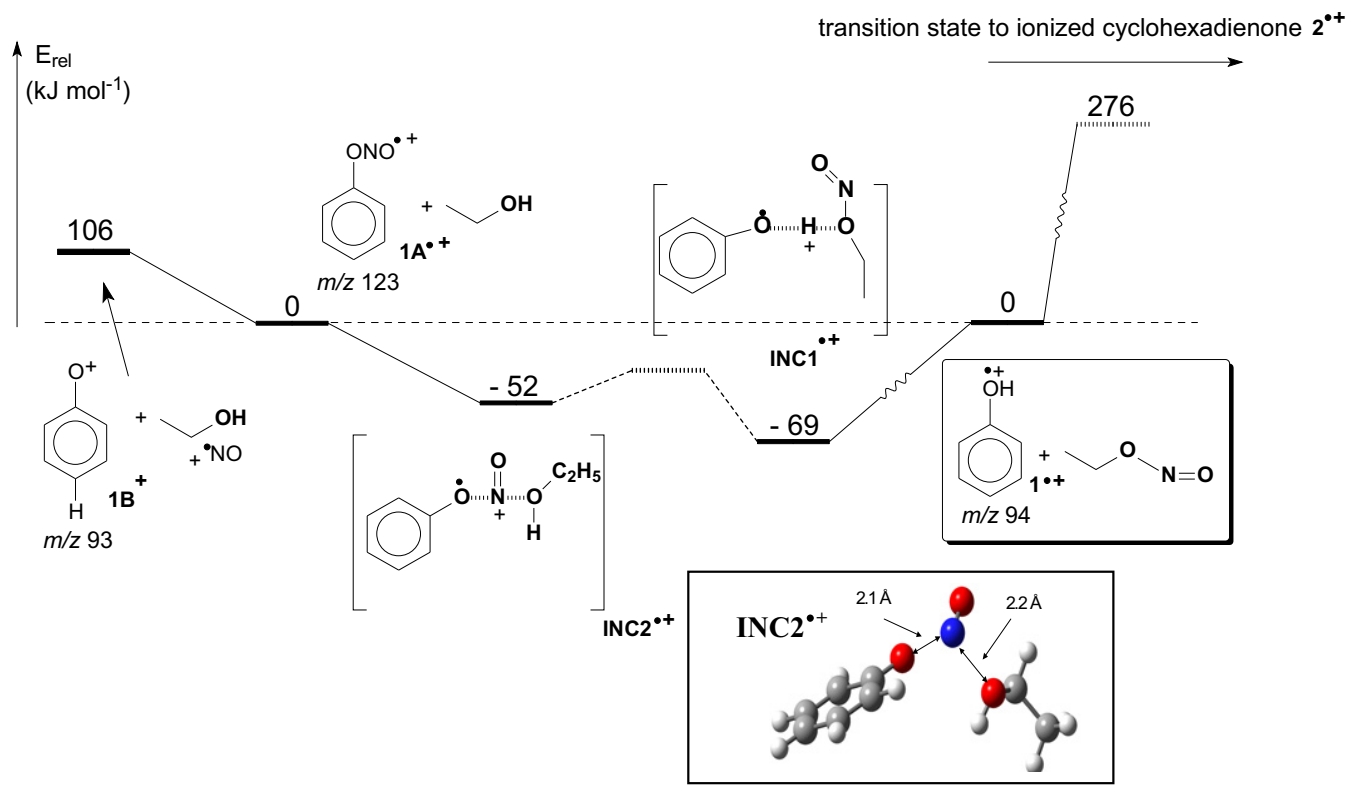

Figure 3. Potential energy diagram showing the ionized phenol $\mathbf{1}^{\bullet+} /$ ethyl nitrite interaction: reaction mechanism for the production of the $\mathrm{m} / \mathrm{z} 123$ radical cations. Relative energies given in $\mathrm{kJ}$ $\mathrm{mol}^{-1}$ were obtained using (U)B3LYP/6-311++G(d,p) + ZPE calculations.

The reaction of ionized enols with $t$-butanol was reported and the authors demonstrated that the complicated reactivity can be explained on the basis of the intermediary of ter-body complexes [17]. In the gas phase, the bimolecular reaction between an ion and a neutral molecule often leads to a weakly bonded species that is termed an ion/molecule complex. These structures are frequently very fluxional and their facile interconversion allows a great number of reactions within the complexes [17]. In the present work, giving the similarity of the studied partners, we will elaborate a multistep mechanism leading to the nitrosation of the phenol ion on the basis of solvated radical cations as key intermediates. The corresponding potential energy diagram is represented in Figure 3.

As exemplified in Scheme 4, in a first step, the interaction between ionized phenol and ethyl nitrite yields the hydrogen-bridged radical cation $\mathrm{INC1}^{{ }^{++}}$ (INC stands for Ion Neutral Complex) in which the hydroxylic hydrogen atom is shared by the phenoxy radical and ethyl nitrite. As presented in Figure 3, the interaction energy for this complex is $69 \mathrm{~kJ} \mathrm{~mol}^{-1}$. In a second step, $\mathrm{INC1}^{\circ+}$ may convert into the complex INC2 $^{-+}$that is really close in energy by a relative rotation of the phenoxy radical on one hand and protonated ethyl nitrite on the other hand. The soobtained species $\mathrm{INC2}^{\circ+}$ can be considered as a terbody complex [17] between ethyl alcohol, the phenoxy radical, and ionized nitric oxide because the bond distances are calculated to amount to 2.1 and $2.2 \AA$ between, respectively, (i) the oxygen atom of the phenoxy radical and the nitrogen atom of the nitric oxide cation and (ii) the same nitrogen atom and the oxygen atom of ethyl alcohol (see Figure 3). This key interme-

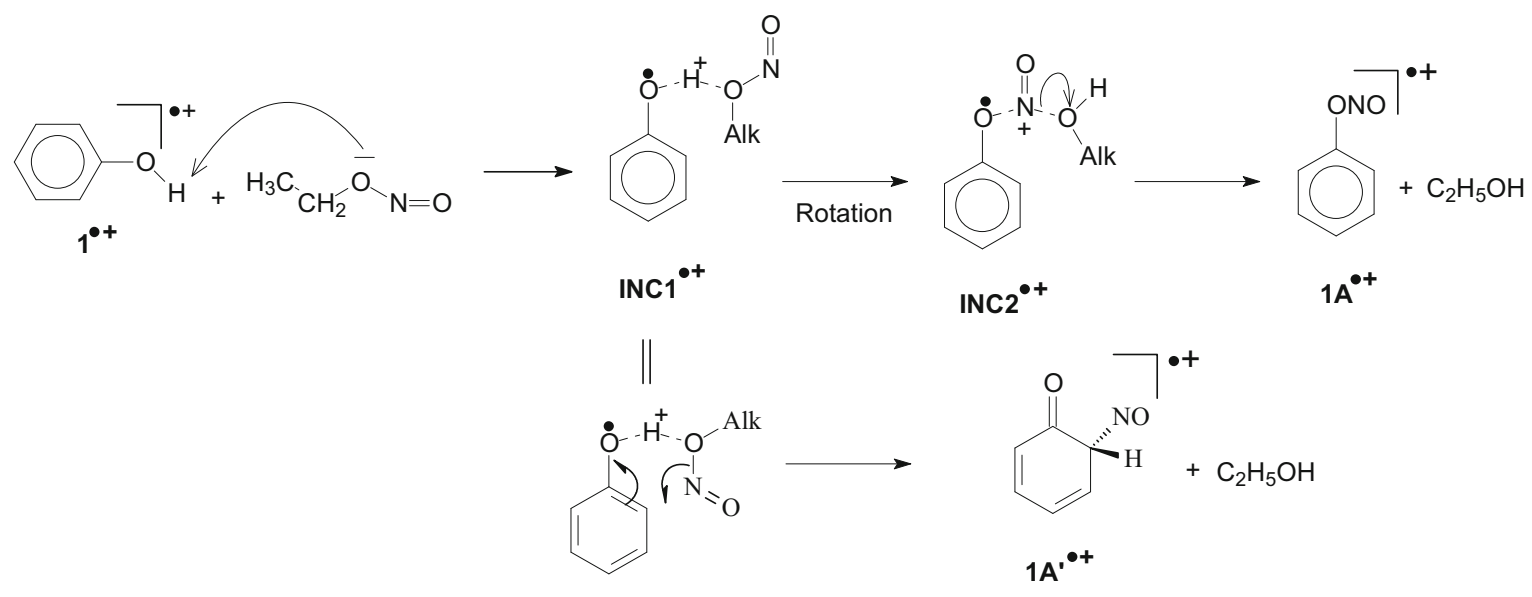

Scheme 4 


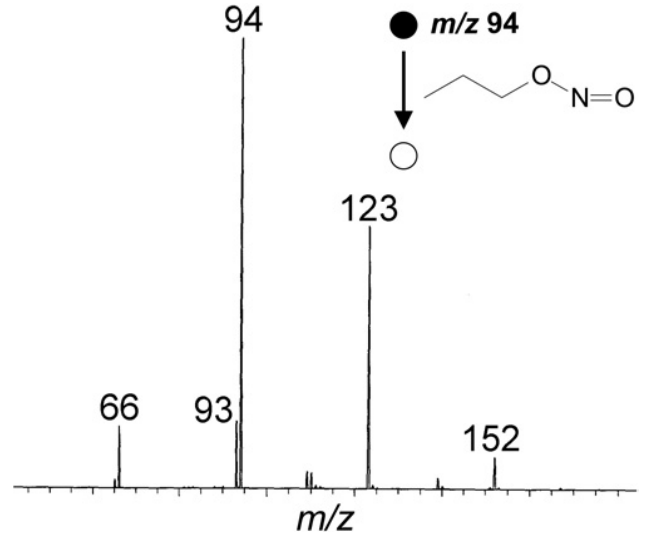

Figure 4. Associative ion/molecule reactions between ionized phenol $\mathbf{1}^{\bullet+}(\mathrm{m} / \mathrm{z} 94)$ and propyl nitrite in the hexapole collision cell: mass spectrum of the reaction products (B scan).

diate is then likely to expel the alcohol molecule, yielding the observed ionized phenyl nitrite species $\left(\mathbf{A A}^{\bullet+}\right)$ (see Scheme 4). It is worth noting that we already proposed the same reaction pathway to explain the nitrosation of ionized enol when reacting with alkyl nitrite [5]. In this context, gas-phase nitrosation of, for instance, ionized vinyl alcohol, $\mathrm{CH}_{2}=\mathrm{CH}-\mathrm{OH}^{\bullet+}$, was proposed to yield, not only ionized vinyl nitrite, $\mathrm{CH}_{2}=\mathrm{CH}-\mathrm{ONO}^{\bullet}$, but also ionized $\alpha$-nitrosoacetaldehyde, $\mathrm{O}=\mathrm{N}-\mathrm{CH}_{2}-\mathrm{C}(=\mathrm{O}) \mathrm{H}^{\bullet+}$ [5]. When applied to the phenol case, the corresponding reaction is expected to afford, beside ionized phenyl nitrite, ionized 6-nitrosocyclohexadienone $\left(\mathbf{1 A}^{\mathbf{t}^{\bullet++}}\right)$, as proposed in Scheme 4 . However, all attempts to optimize ionized $\mathbf{1 A}^{\prime \cdot+}$ at the level of theory selected for the present study invariably converged to ionized phenyl nitrite $\left(\mathbf{1 A}^{\boldsymbol{\bullet}}\right)$.

\section{Associative Ion/Molecule Reactions between Ionized Phenol $\mathbf{1}^{\bullet+}$ and Ethyl Nitrite: Structural Characterization of $\mathrm{m} / \mathrm{z} 138$ Ions}

Beside $m / z 93$ and 123 cations, the interaction between ionized phenol $\mathbf{1}^{\mathbf{}+}$ and ethyl nitrite in the Hcell also affords $m / z 138$ radical cations (see Figure 1). Composition of the so-produced ions is readily identified as $\left[1^{{ }^{*+}}\right.$ $\left.+\mathrm{C}_{2} \mathrm{H}_{5} \mathrm{O}^{\bullet}-\mathrm{H}^{\bullet}\right]^{\bullet+}$ and then those ions are generated by a formal radical substitution in ionized phenol of an hydrogen atom by the ethoxy radical. The nature of the $\mathrm{m} / \mathrm{z} 138$ was easily confirmed when reacting ionized phenol with propyl nitrite instead of ethyl nitrite and observing the displacement of the signal from $\mathrm{m} / \mathrm{z} 138$ (Figure 1) to $\mathrm{m} / \mathrm{z} 152$ (Figure 4), the 14 uma shift corresponding to the incorporation of the $\mathrm{CH}_{3} \mathrm{CH}_{2} \mathrm{CH}_{2} \mathrm{O}$ chain when reacting with propyl nitrite.

On the basis of the composition of the $\mathrm{m} / \mathrm{z} 138$ ions( i.e., $\left[1^{\bullet+}+\mathrm{C}_{2} \mathrm{H}_{5} \mathrm{O}^{\bullet}-\mathrm{H}^{\bullet}\right]^{\bullet+}$ ) and starting from the structures of the reacting species, the ions presented in Scheme 5 can be envisaged as potential candidates. First of all, if the leaving hydrogen atom is the phenolic one, ionized ethyl phenyl peroxide $\left(\mathbf{1 C}^{\bullet+}\right)$ or the isomeric ethoxycyclohexadienone molecular ions $\left(\mathbf{1 D}^{\bullet+}\right.$ and $1 \mathrm{E}^{\bullet+}$ ) can be proposed.

On the other hand, if the substituted hydrogen atom belongs to the ring hydrogen atoms, ethoxyphenol molecular ions are likely to be obtained $\left(\mathbf{1 F}^{{ }^{++}}\right.$and $\mathbf{1 G}^{\bullet+}$ ). The species to be examined are presented in Scheme 5 together with their relative energies obtained at the (U)B3LYP / 6-311++G(d,p) + ZPE level of theory. As expected, the phenol ions $\left(1 \mathrm{~F} / \mathrm{G}^{\bullet+}\right)$ represent the most stable isomers, whereas ionized peroxide $1 \mathrm{C}^{\bullet+}$ is more than $270 \mathrm{~kJ} \mathrm{~mol}^{-1}$ less stable than 4-ethoxyphenol molecular ion $\left(\mathbf{G G}^{\bullet+}\right)$. Ionized ethoxycyclohexadienone $\left(1 \mathrm{D} / \mathrm{E}^{\bullet+}\right)$ ions are also calculated to be around $150-200$ $\mathrm{kJ} \mathrm{mol}^{-1}$ less stable. At first sight, it is thus tempting to conclude that $\mathrm{m} / \mathrm{z} 138$ radical cations, prepared by reaction between ionized phenol and ethyl nitrite, are either ions $\mathbf{1 F}^{\bullet+}$ or $\mathbf{1 G}^{\bullet+}$. However, the CA spectrum (not shown) of the $\mathrm{m} / \mathrm{z} 138$ radical ions under investigation is somewhat different from the CA spectra of both the referent ions, 2- and 4-ethoxyphenol $\left(\mathbf{1 F} / \mathrm{G}^{\bullet+}\right)$, generated by electron ionization of the corresponding neutral molecules. Nevertheless, the weak, but significant because reproducible, differences cannot be used to determine the actual structure of the $\mathrm{m} / \mathrm{z} 138$ ions.

Identification of the leaving hydrogen atom then appears to be required to obtain additional pieces of information. The interaction in the Hcell between ionized phenol- $d_{5}\left(\mathbf{1}_{-} \mathbf{d}_{\mathbf{5}}{ }^{\bullet+}, \mathrm{m} / \mathrm{z}\right.$ 99) and ethyl nitrite has been studied and the recorded mass spectrum, presented in Figure 5, is really informative. First, this experiment readily confirms the conclusions obtained previously when studying the $\mathrm{m} / \mathrm{z} 123$ radical cations. Indeed, the $m / z 123$ signal, observed in Figures 1 and 4 and corresponding to ionized phenyl nitrite, is now detected at $\mathrm{m} / \mathrm{z} 128$. The observed 5 uma difference (5 deuterium atoms instead of 5 hydrogen atoms) unambiguously confirms that the phenolic hydrogen atom is abstracted on the way to the $m / z$ 123(128) radical cations. In the same vein, the signal $\mathrm{m} / \mathrm{z} 138$ (in Figure 1) is now observed at $m / z 143$ (in Figure 5) and therefore the so-produced ions retain 5 deuterium atoms. In other words, again the leaving hydrogen atom originates from the hydroxylic moiety and not from the ring. This observation, although in contrast with the calculated

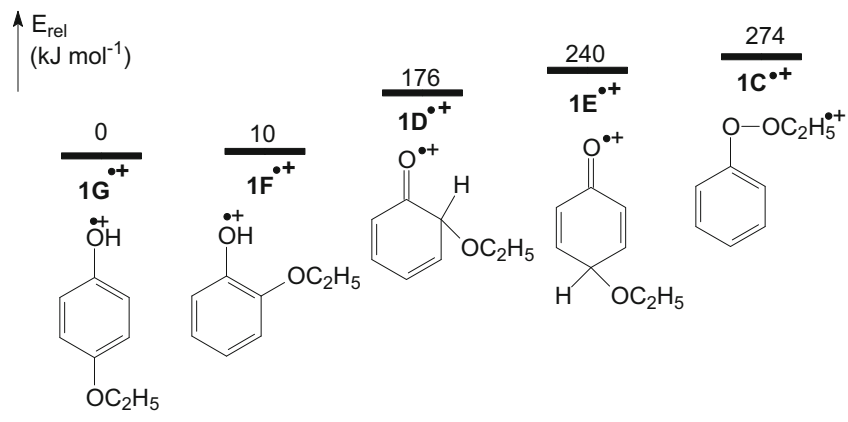

Scheme 5. Relative energies given in $\mathrm{kJ} \mathrm{mol}^{-1}$ obtained from (U)B3LYP/6-311++G(d,p) + ZPE calculations. 


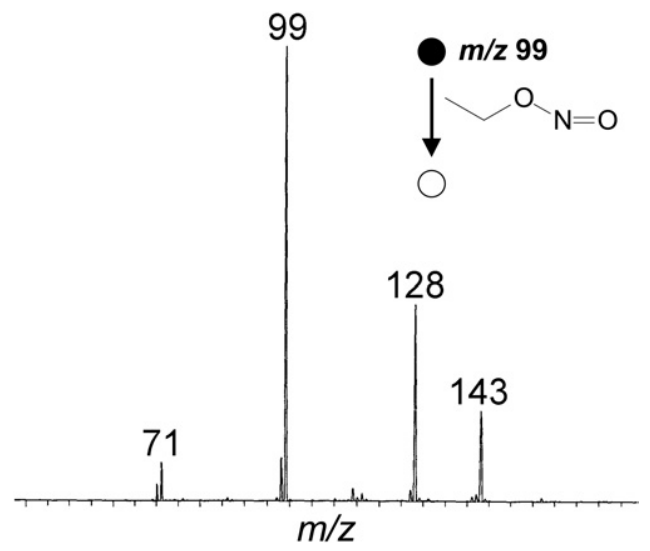

Figure 5. Associative ion/molecule reactions between ionized phenol $\mathbf{1}-\mathbf{d}_{\mathbf{5}}{ }^{+}(\mathrm{m} / \mathrm{z}$ 99) and ethyl nitrite in the hexapole collision cell: mass spectrum of the reaction products (B scan).

relative energies presented in Scheme 5, points to the presence of ions $1 \mathrm{C}^{\bullet+}, \mathbf{1 D}^{\bullet+}$, or $1 \mathrm{E}^{\bullet+}$.

Among all the resonance structures possible for the phenol molecular ions, the structures $\mathbf{1}^{\prime \bullet+}$, presented in Scheme 6, reveal a distonic [18] or distonoid [19] character that could explain the reactivity of ionized phenol by the presence of a non-negligible spin density in the ortho positions. Consequently, we tentatively propose the pathway described in Scheme 7 . The reaction is initiated by a nucleophilic attack of the phenolic hydrogen atom by the lone pair of electrons of the nitrogen atom present in the nitrite group. In the so-obtained ion neutral complex INC $3^{\circ+}$, the hydrogen bond created between the phenoxy radical and the ethyl nitrite molecule positions both partner to allow the transfer of the ethoxy radical from the nitrite molecule to the ortho radical site of the phenol molecular ion. Ionized 6-ethoxycyclohexadienone $\mathbf{1 D}^{\boldsymbol{*}+}$ is then finally obtained by loss of a $\mathrm{H}-\mathrm{N}=\mathrm{O}$ molecule from the INC4 ${ }^{\bullet+}$ intermediate.

It is worth mentioning that both the mechanisms leading, on one hand, to the $\mathrm{m} / \mathrm{z} 123$ radical cations (Scheme 4) and, on the other hand, to the $\mathrm{m} / \mathrm{z} 138$ radical cations (Scheme 7) are initiated by the sharing of a lone pair of electrons of the neutral reagent with the phenolic hydrogen atom. The major difference is that the binding concerns, in one case, the ether-like oxygen atom and, in the other case, the nitrogen atom of the nitrite function. To test whether this duality is energetically possible, the mechanism of the second reaction was also theoretically approached at the B3LYP/6-311++G(d,p) level of theory. The obtained potential energy diagram is presented in Figure 6. The most interesting piece of information is that production of the intermediate ion neutral complex $\mathrm{INC}^{\circ}+$ is not only an exothermic process, releasing about $60 \mathrm{~kJ} \mathrm{~mol}^{-1}$, but is also competitive with production of the INC1 ${ }^{\bullet+}$ complex ion on the way to the $\mathrm{m} / \mathrm{z} 123$ ions (see Scheme 8).

With respect to the ultimate production of the $\mathrm{m} / \mathrm{z}$ 138 ions, the overall process is calculated to be $130 \mathrm{~kJ}$ $\mathrm{mol}^{-1}$ endothermic. As mentioned earlier in the context of the previous observation of $\mathrm{m} / \mathrm{z} 93$ cations, the occurrence of endothermic processes in our experimental setup is not unexpected because no thermalization step precedes the ion/molecule reaction processes and therefore hot ions cannot be expelled from the ion beam. In the present case, the maximum excess of internal energy in the phenol ions before the reaction is estimated to be about $276 \mathrm{~kJ} \mathrm{~mol}^{-1}$, which is the energy barrier to the decarbonylation process of $\mathbf{1}^{\cdot+}$ that spontaneously occurs in the hexapole cell $(\mathrm{m} / \mathrm{z} 66$ ions in Figure 1). Consequently, a part of the reactive ions carries enough internal energy to allow the $\mathrm{m} / \mathrm{z} 138$ ions to be produced through the calculated endothermic process.

\section{Associative Ion/Molecule Reactions between Ionized Cyclohexadienone $\mathbf{2}^{\bullet+}$ and Ethyl Nitrite}

Considering the ion/molecule reaction between $2^{\circ+}$ and ethyl nitrite (see Figure 7), the dominant ionic products are now detected at $\mathrm{m} / \mathrm{z} 111$ ( $\mathrm{HO}^{\bullet}$ addition), $\mathrm{m} / \mathrm{z} 123$ (ionized phenyl nitrite), $\mathrm{m} / \mathrm{z} 138$ (ionized 6-ethoxycyclohexadienone), $\mathrm{m} / \mathrm{z} 139\left(\mathrm{C}_{2} \mathrm{H}_{5} \mathrm{O}^{\bullet}\right.$ addition), and $m / z \quad 140 \quad\left(\mathrm{NO}_{2}{ }^{\circ}\right.$ addition); $m / z \quad 66$ ions (i.e., $[2-\mathrm{CO}]^{\cdot+}$ ) are also detected and come from the metastable decomposition of mass-selected $\mathrm{m} / \mathrm{z} 94$ radical cations. First of all, the gas-phase behaviors of $\mathbf{1}^{\bullet+}$ and $2^{\cdot+}$ in the presence of ethyl nitrite are thus clearly different and consequently allow the characterization of both structures. However, the observation of some similar ion/molecule reaction products, such as $\mathrm{m} / \mathrm{z} 123$ and 138 ions, strongly suggests the occurrence of a mixture of both isomers. Actually, a minute comparison of the spectra presented in Figures 1 and 7 reveals (i) that $m / z 123$ and 138 ions are always detected irrespective of the preparation modes of the mass-selected $\mathrm{m} / \mathrm{z}$ 94 ions, direct electron ionization of phenol, or dissociative ionization of DODA (see Scheme 2); and (ii) that $\mathrm{m} / \mathrm{z} 111,139$, and 140 ions are significantly observed only when the reactive ions are prepared from DODA. Therefore, we propose that direct electron ionization of phenol upon EI conditions affords only phenol molecular ions $\mathbf{1}^{\boldsymbol{O}^{+}}$as stable ions. All the radical cations that overcome the transition barrier toward $2^{\bullet+}$ radical cations contribute to the unstable and metastable $\mathbf{2}^{\cdot+}$ ion populations. Whereas the lifetime of the unstable $2^{\bullet+}$ ions by definition is shorter than the source resi-

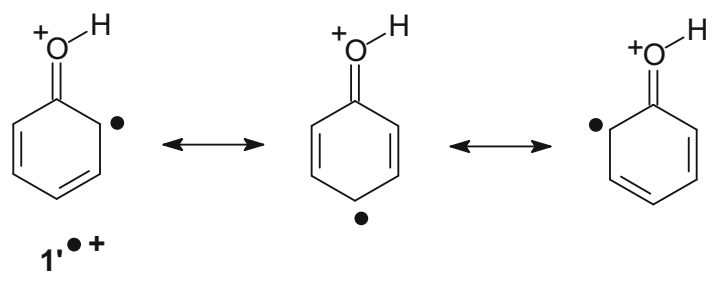

Scheme 6 


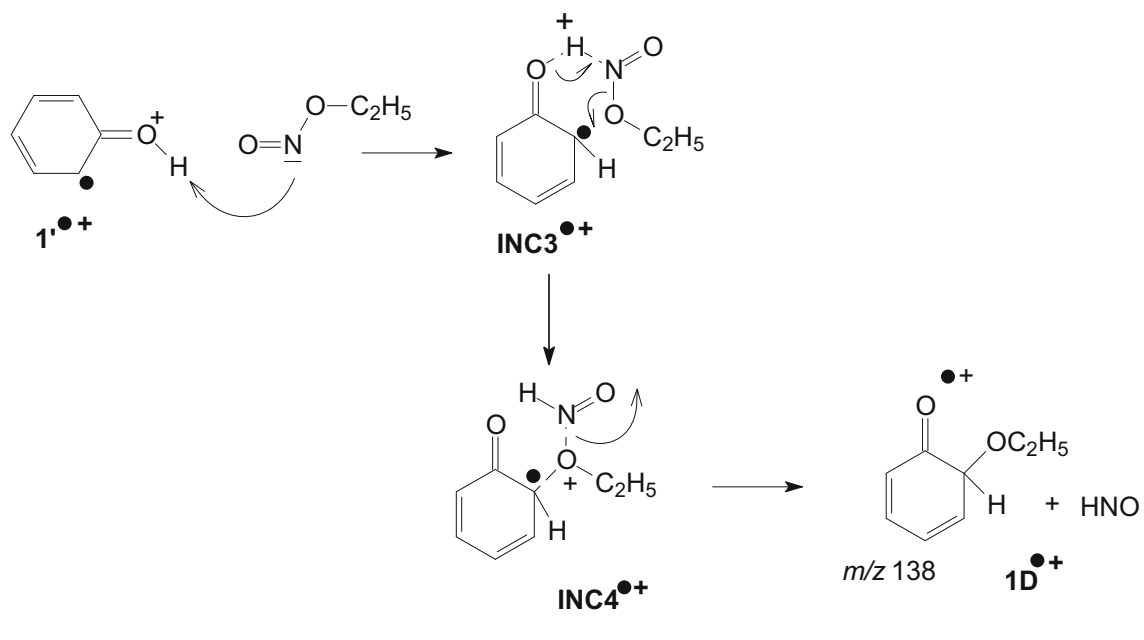

Scheme 7

dence time, the metastable $2^{\bullet+}$ ions, on the other hand, are stable enough to leave intact the ion source but spontaneously decompose in the hexapole cell and only the $m / z 66$ fragment ions are detected. With respect to the $\mathrm{m} / \mathrm{z} 94$ ion beam prepared by dissociative ionization of DODA, both $\mathbf{1}^{\bullet+}$ and $\mathbf{2}^{\bullet+}$ ions seem to be present in the ion beam in amounts large enough to allow their specific ion/molecule reaction products to be competitively observed. The origin of ionized phenol in the ion beam prepared from DODA will subsequently be explained.

At this point of the work, concerning the reaction between $2^{\circ+}$ ions and ethyl nitrite, the structures of the ion/molecule reaction products as well as the mechanisms of the corresponding processes deserve to be examined.

First, because the additions of $\mathrm{HO}^{\circ}(\mathrm{m} / \mathrm{z}$ 111), $\mathrm{C}_{2} \mathrm{H}_{5} \mathrm{O}^{\bullet}\left(m / z\right.$ 139), and $\mathrm{NO}_{2}{ }^{\bullet}(m / z$ 140) are radical processes, it is reasonable to believe that the $3^{\bullet+}$ distonic ion (see Scheme 1) represents the reactive species rather than the cyclic counterpart, ionized cyclohexadienone $2^{\bullet+}$. Actually, the isomerization process $2^{\bullet+} \rightarrow$ $3^{\bullet+}$ is likely to spontaneously occur in the ion source because, as indicated earlier in Scheme 1, the corresponding critical energy is negligible, about $8 \mathrm{~kJ} \mathrm{~mol}^{-1}$ above $2^{\circ+}$, and because the distonic ion $3^{\circ+}$ represents the most stable isomer, being $26 \mathrm{~kJ} \mathrm{~mol}^{-1}$ more stable than the cyclic species $2^{\bullet+}$ [8]. Such a reactivity was already demonstrated in the case of electron ionization of cyclobutanone. Indeed, the well-characterized ${ }^{-} \mathrm{CH}_{2} \mathrm{CH}_{2} \mathrm{CH}_{2} \mathrm{C}^{+} \mathrm{O} \gamma$-distonic species is readily produced by electron ionization and subsequent spontaneous ring opening of cyclobutanone [20].

A distonic structure like $3^{\bullet+}$ was already demonstrated to initiate, with a given neutral reagent, radical

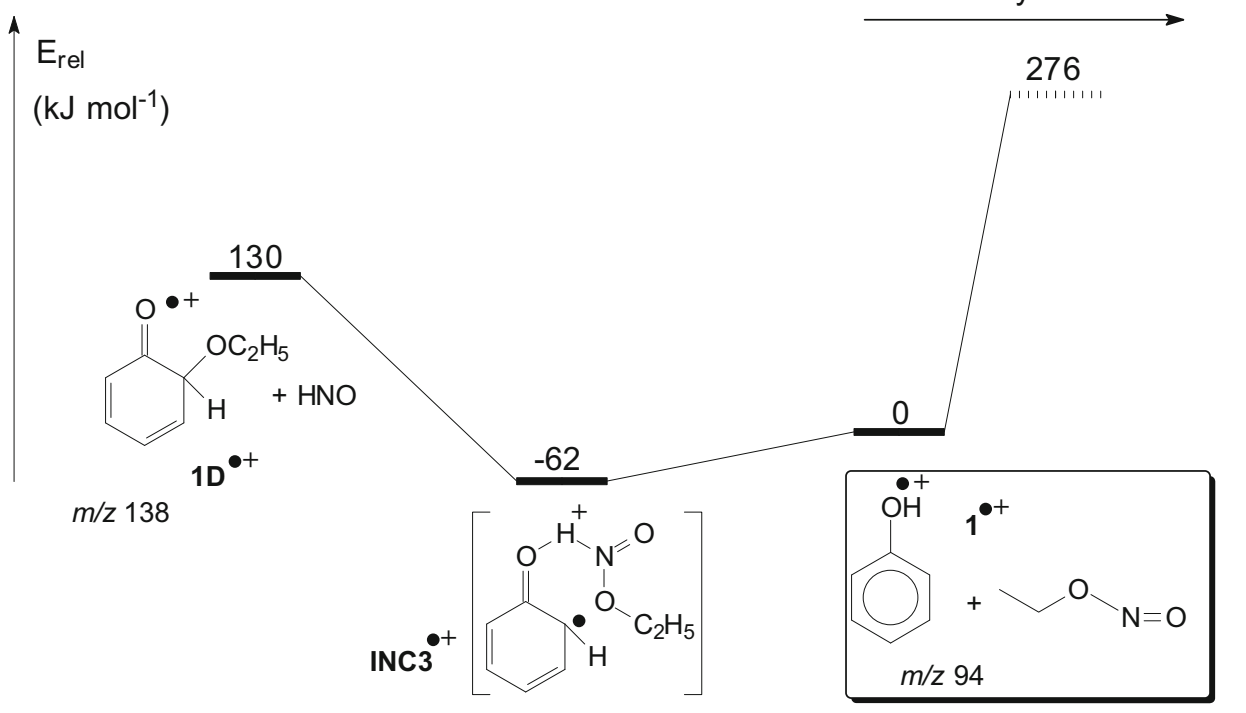

Figure 6. Potential energy profile illustrating the ionized phenol $\mathbf{1}^{\bullet+}$ /ethyl nitrite interaction: reaction mechanism for the production of the $\mathrm{m} / \mathrm{z} 138$ radical cations. Relative energies given in kJ $\mathrm{mol}^{-1}$ were obtained from (U)B3LYP/6-311++G(d,p) + ZPE calculations. 

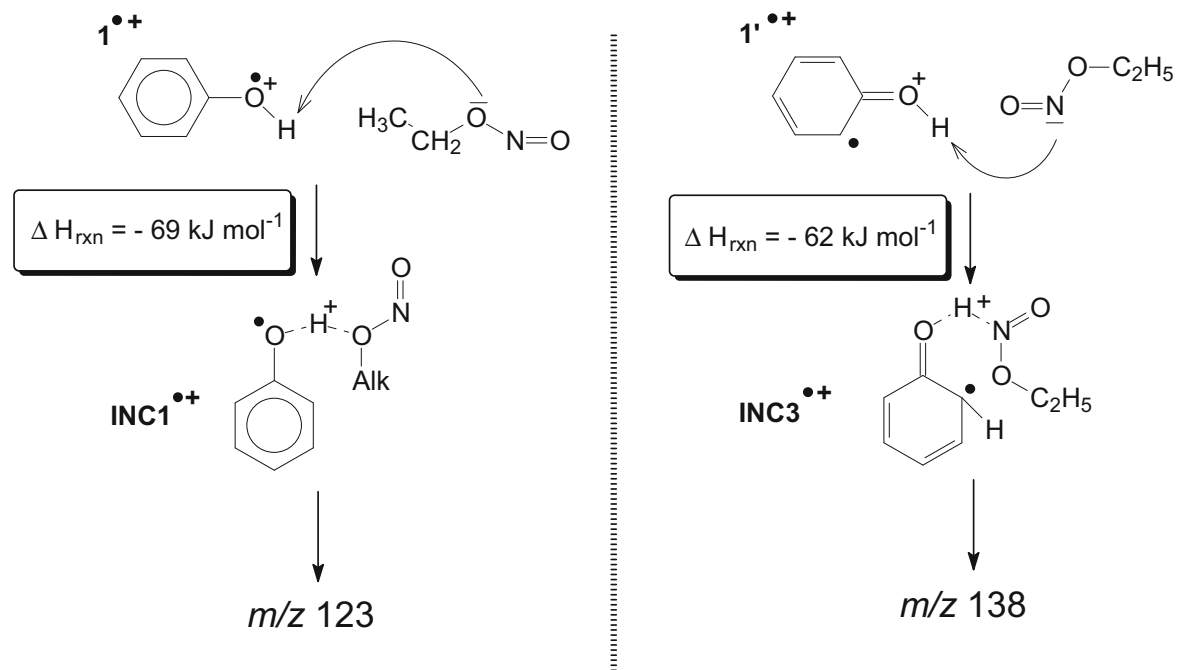

Scheme 8

processes catalyzed by the positive charge [21]. As sketched in Scheme 9, the additions of $\mathrm{NO}_{2}{ }^{\circ}$ and ${ }^{\circ} \mathrm{OC}_{2} \mathrm{H}_{5}$ to the distonic ion $3^{\bullet+}$ may be easily visualized by a free-radical reaction where a $-\mathrm{H}_{2} \mathrm{C}-\mathrm{O}$ or $-\mathrm{H}_{2} \mathrm{C}-\mathrm{N}$ bond is created; $m / z 139$ are then produced by the homolytic cleavage of the $\mathrm{O}-\mathrm{NO}$ bond and radical addition of the ${ }^{\bullet} \mathrm{OC}_{2} \mathrm{H}_{5}$ radical to the methylene group of the distonic ion. The consecutive loss of ethene from the $\mathbf{3} \mathbf{A}^{+}$yields $\mathbf{3} \mathbf{B}^{+}$cations detected at $m / z 111$ in the mass spectrum (Figure 7). Competitively, the homolytic breaking of the $\mathrm{C}_{2} \mathrm{H}_{5}-\mathrm{ONO}$ bond in the neutral reagent and the radical addition of the $\mathrm{NO}_{2}{ }^{\circ}$ radical on the methylene group of the distonic ion afford $3 \mathrm{C}^{+}$or $3 C^{\prime+}$ cations $(m / z 140)$. Acylium structures are therefore tentatively ascribed to the $m / z 111,139$, and 140 ions originally produced, respectively, by addition of $\mathrm{HO}^{\bullet}$, $\mathrm{C}_{2} \mathrm{H}_{5} \mathrm{O}^{\bullet}$, and $\mathrm{NO}_{2}{ }^{\bullet}$ to the $3^{\bullet+}$ ions (see Scheme 9 ).

These experimental results are supported by DFT calculated data presented in Figure 8, which reveals that both reactions leading to $\mathbf{3} \mathbf{A}^{+}$and $\mathbf{3} \mathbf{B}^{+}$cations $(\mathrm{m} / \mathrm{z}$ 139 and 111) are exothermic processes and then energetically allowed. On the other hand, the reaction yielding $3 \mathrm{C}^{+}$cations $(\mathrm{m} / \mathrm{z} 140)$ from $2^{\bullet+}$ radical cations is calculated to be $70 \mathrm{~kJ} \mathrm{~mol}^{-1}$ endothermic and is then a priori not favorable in the gas phase. However, the absence of a thermalization step on our experimental setup allows slightly endothermic process to be allowed. Finally, the isomeric nitro structure, $3 \mathrm{C}^{\prime+}$, could also be envisaged for the $\mathrm{m} / \mathrm{z} 140$ cations. Indeed, our DFT calculations reveal that $3 \mathrm{C}^{\prime+}$ cations (Scheme 9 ) are only $6 \mathrm{~kJ} \mathrm{~mol}^{-1}$ less stable than the isomeric $3 \mathrm{C}^{+}$ cations. Such a value cannot be considered as significant because (i) all the different conformations of both ions were not investigated and (ii) at the B3LYP/6$311++\mathrm{G}(\mathrm{d}, \mathrm{p})$ level of theory, an error bar of about \pm 8 $\mathrm{kJ} \mathrm{mol}^{-1}$ on the calculated relative energies can be expected [1](b).
Associative Ion/Molecule Reactions between Ionized Cyclohexadienone $\mathbf{2}^{\bullet+}$ and Ethyl Nitrite: Origin of the Phenol Molecular Ions $\mathbf{1}^{\circ+}$

Molecular ions of phenol $\left(\mathbf{1}^{\bullet+}\right)$ are then detected in the $m / z 94$ ion beam prepared from DODA because specific ion/molecule reaction products are observed at $\mathrm{m} / \mathrm{z} 123$ and 138. This contribution is not straightforward to explain and therefore we decided to examine the potential origins in greater detail. At this point of the discussion, it is important to remember that ionized phenol $\left(\mathbf{1}^{\bullet+}\right)$ is more stable than ionized cyclohexadienone $\left(2^{\bullet+}\right)$ by about $150 \mathrm{~kJ} \mathrm{~mol}^{-1}$ [8].

Solid DODA is not a very volatile compound and requires significantly high introduction temperatures to get appropriate ion currents. Given its particular (polycyclic) structure and the pressure/temperature conditions used, thermal decomposition cannot be com-

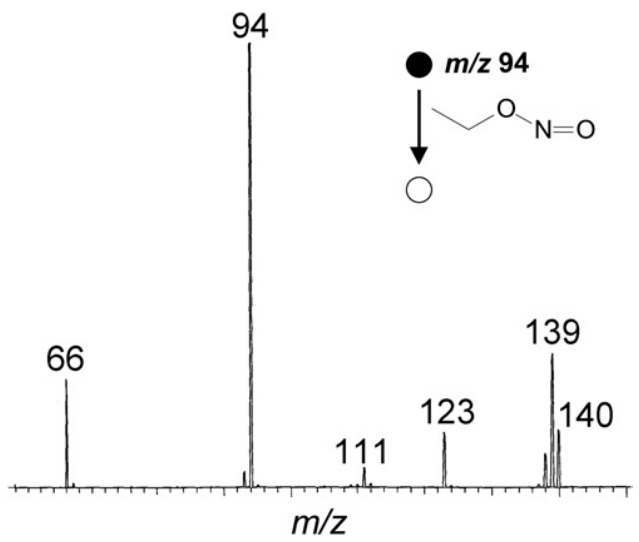

Figure 7. Associative ion/molecule reactions between massselected $\mathrm{m} / \mathrm{z} 94$ radical cations obtained by dissociative ionization of 2,5-dioxo-bicyclo[2.2.2]octan-7,8-dicarboxylic anhydride (DODA), and ethyl nitrite in the hexapole collision cell: mass spectrum of the reaction products (B scan). 


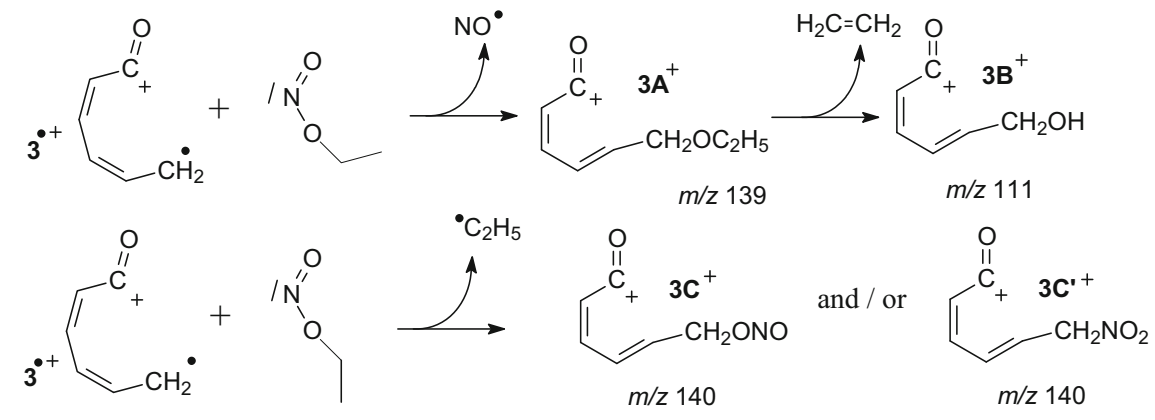

Scheme 9

pletely excluded. If some neutral cyclohexadienone is indeed formed, its tautomerization into phenol is expected to occur readily by wall collisions [22]. We have therefore applied pure flash-vacuum pyrolysis (FVP) conditions, as those described in Brown et al. [23], in a 200-800 ${ }^{\circ} \mathrm{C}$ temperature range with real-time monitoring of the conventional EI mass spectrum and the CA spectrum of the $m / z 94$ ions. No increase of the telltale $\mathrm{m} / \mathrm{z} 55$ signal — characteristic of ionized phenol [7]—is noticed upon modification of the pyrolyzer temperature. We can thus conclude that the $\mathrm{m} / \mathrm{z} 94$ ion beam prepared by dissociative ionization of the DODA precursor and reaching the Hcell is mainly or exclusively constituted by ionized cyclohexadienone $2^{\bullet+}$ without the presence of phenol ions.

Consequently, an isomerization process catalyzed by the approach of the neutral reactant should be considered. Actually, numerous experimental and theoretical studies have recently reported rearrangement of ionized carbonyl compound to the more stable enol ion by proton transfer through bimolecular interaction with an appropriate base. Such a process, termed "proton-transfer catalysis" [24], was shown to efficiently catalyze the enolization of acetaldehyde [25], acetone [26], acetophe- none [27], and acetamide [28] molecular ions in reducing the corresponding critical barrier. It was demonstrated that the required condition for the efficient proton-transfer catalysis of an $[\mathrm{H}-\mathrm{X}-\mathrm{Y}]^{\bullet+}$ ion into its isomeric more stable form $[\mathrm{X}-\mathrm{Y}-\mathrm{H}]^{\bullet+}$, the so-called Radom transport criterion [29], is that the proton affinity (PA) of the catalyst lies between the PA values of the conjugate base $[\mathrm{X}-\mathrm{Y}]^{\bullet}$ at $\mathrm{X}$ and at $\mathrm{Y}$.

We therefore calculated at the B3LYP/6$311++G(d, p)$ level of theory the PAs of the different species concerned by the proton-transfer catalyzed isomerization of ionized cyclohexadienone into ionized phenol with ethyl nitrite as the base responsible for the tautomerization. As presented in Scheme 10, O-protonation of ethyl nitrite by ionized cyclohexadienone $\left(2^{\bullet+}\right)$ is an energetically allowed process, given that the PA of ethyl nitrite, $794 \mathrm{~kJ} \mathrm{~mol}^{-1}$, is calculated to be higher than the $\mathrm{PA}_{C}$ of the phenoxy radical at the ring carbon atom: $\mathrm{PA}_{\mathrm{C}}=786 \mathrm{~kJ} \mathrm{~mol}{ }^{-1}$. This first step is immediately followed, inside the encounter complex, by the protonation of the phenoxy radical on the oxygen atom because the PA of this radical at the oxygen atom- $-\mathrm{PA}_{\mathrm{O}}=857 \mathrm{~kJ} \mathrm{~mol}^{-1}$-is higher than the PA of ethyl nitrite $\left(794 \mathrm{~kJ} \mathrm{~mol}^{-1}\right.$ ) [The $\mathrm{PA}_{\mathrm{O}}$ value $(857 \mathrm{~kJ}$

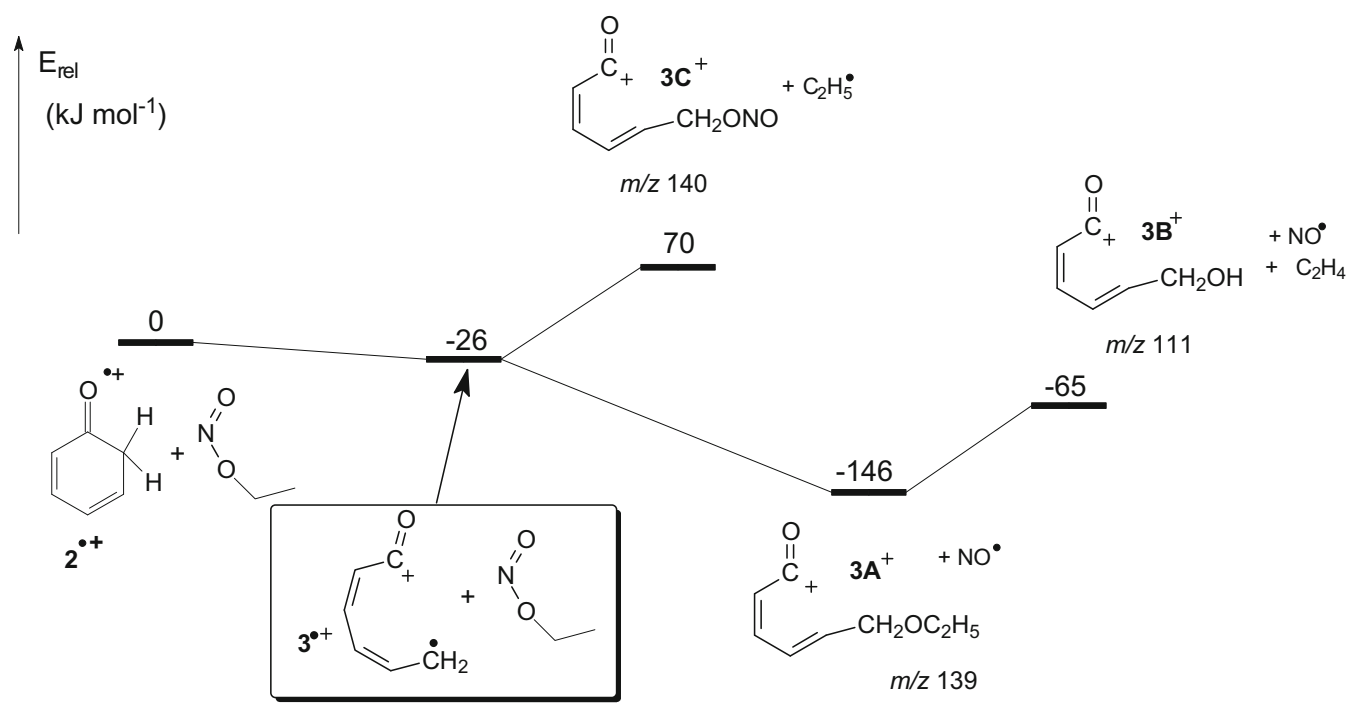

Figure 8. Potential energy diagram for the $2 / 3^{\bullet+}$ ions/ethyl nitrite interaction. Relative energies given in $\mathrm{kJ} \mathrm{mol}^{-1}$ were obtained from (U)B3LYP/6-311++G(d,p) + ZPE calculations. 


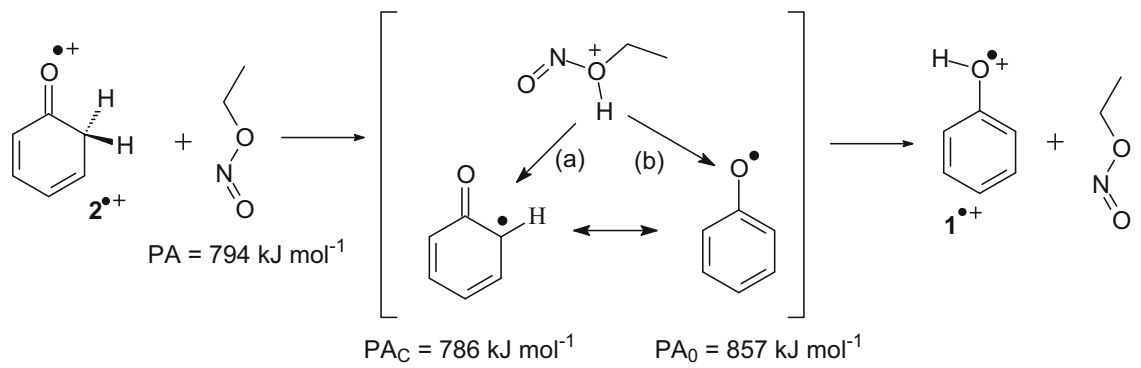

Scheme 10

$\mathrm{mol}^{-1}$ ) for the phenoxy radical obtained at the B3LYP/ $6-311++G(d, p)$ level of theory can be compared to the reported data [6], $856 \mathrm{~kJ} \mathrm{~mol}^{-1}$; moreover, the adequacy between both values confirms the reliability of our calculations.] This second protonation reaction then affords ionized phenol $\left(\mathbf{1}^{\bullet+}\right)$.

This is a new example of a proton-transfer-catalyzed isomerization, then leading to ionized phenol $\left(\mathbf{1}^{\boldsymbol{+}}\right)$ from ionized cyclohexadienone $\left(2^{\bullet+}\right)$ with ethyl nitrite as the catalyst. This overall process from $\mathbf{2}^{\bullet+}$ to $\mathbf{1}^{\bullet+}$ is competitive to the observed associative ion/molecule reactions of ions $2^{\bullet+}$ described earlier. The phenol molecular ions obtained in the Hcell, thus produced, can then consecutively react with ethyl nitrite specifically producing $\mathrm{m} / \mathrm{z} 123$ and 138 radical cations. This is, to the best of our knowledge, the first example of an associative ion/molecule reaction process involving the isomerization, by the neutral reagent, of the massselected ions before the structural-specific reactions.

\section{Conclusions}

The distinction of gaseous ionized phenol $\left(\mathbf{1}^{\bullet+}\right)$ and ionized cyclohexadienone $\left(2^{\bullet+}\right)$ suggested by slightly different high-energy CA spectra is in fact more readily achieved by studying their associative ion/molecule interactions with ethyl nitrite in a hexapole collision cell installed in a large-scale six-sector mass spectrometer. Ionized phenyl nitrite and ionized 6-ethoxycyclohexadienone are produced when ionized phenol reacts with the neutral nitrite. The observation of the radical addition of the ethoxy chain on a ring carbon atom is a new example of the reactivity of distonoid/distonic radical cations. Free-radical reactions $\left(\mathrm{NO}_{2}{ }^{\circ}, \mathrm{C}_{2} \mathrm{H}_{5} \mathrm{O}^{\circ}\right.$, and $\mathrm{OH}^{\bullet}$ abstractions) are specific reactions of ionized cyclohexadienone $\left(2^{\bullet+}\right)$. The occurrence of these radical abstractions is probably consecutive to a spontaneous ring opening of the cyclohexadienone radical ion to a distonic species $3^{\bullet+}$. The proposed mechanism relies on radical reactions catalyzed by initial electrostatic interaction between the charge site of the distonic ion and the neutral reagent. The so-obtained intermediate allows the reaction partners to adequately position themselves inside the encounter complex for the subsequent slower radical reactions. We also demonstrated that ionized cyclohexadienone is isomerized during a pro- ton-transfer catalysis process into ionized phenol inside the Hcell with ethyl nitrite as the base. The molecular ions of phenol generated under these conditions consecutively undergo reactions producing $\mathrm{m} / \mathrm{z} 123$ and 138 radical cations. Our proposed reaction products and molecular mechanisms are fully supported by quantum chemical calculations at the (U)B3LYP/6-311++G(d,p) + ZPE level of theory.

\section{Acknowledgments}

Personnel from the Mons laboratory thank the "Fonds National de la Recherche Scientifique" for its contribution to the acquisition of a large-scale tandem mass spectrometer, Waters AutoSpec 6F. P.G. (FRS-FNRS Research associate) also thanks the FRS-FNRS for continuing support. M.T.N. is indebted to the KULeuven Research Council (GOA and IUPA Programs) and FWO-Vlaanderen.

\section{References}

1. (a) Bouchoux, G. Enol Ions. In The Encyclopedia of Mass Spectrometry. Fundamentals of and Applications to Organic (and Organometallic) Compounds, Vol. 4, Nibbering, N. M. N., Ed. Elsevier: Amsterdam, 2005; pp 135-144; (b) Nguyen, M. T.; Kryachko, E. S.; Vanquickenborne, L. G. In The Chemistry of Phenols, Rappoport, Z. Ed. Wiley: Chichester, UK, 2003; Chapter 1, pp 1-198; (c) Nibbering, N. M. M. An ICR Study on the Structure of the $\mathrm{C}_{6} \mathrm{H}_{6} \mathrm{O}^{\bullet+}$ Ion from Phenetole. Tetrahedron. 1973, 29, 385-390.

2. Turecek, F.; Cramer, C. J. The Thermochemistry of Simple Enols and Enol Cation Radicals Revisited. A G2(MP2) Ab Initio Study. J. Am. Chem. Soc. 1995, 117, 12243-12253.

3. Bertrand, W.; Bouchoux, G. Keto-Enol Tautomerism and Dissociation of Ionized Acetaldehyde and Vinyl Alcohol. A G2 Molecular Orbital Study. Rapid Commun. Mass Spectrom. 1998, 12, 1697-1700.

4. Gronert, S. Mass Spectrometric Studies of Organic Ion/Molecule Reactions. Chem. Rev. 2001, 101, 329-360.

5. Gerbaux, P.; Wantier, P.; Nam, P. C.; Nguyen, M. T.; Bouchoux, G. Flammang, R. A Specific Gas-Phase Substitution Reaction between Enol Radical Cations and t-Butyl Nitrite. Eur. J. Mass Spectrom. 2004, 10, 889-898.

6. Lias, S. G.; Bartmess, J. E.; Liebman, J. F.; Holmes, J. L.; Levin, R. D.; Mallard, W. G. Gas-Phase Ion and Neutral Thermochemistry. J. Phys. Chem. Ref. Data Suppl. 1988, 1, 17.

7. (a) Anderson, S. C.; Goodman, L., Krogh-Jespersen, K., Ozkabak, A. G.; Zare, R. N. Multiphoton Ionization Photoelectron Spectroscopy of Phenol: Vibrational Frequencies and Harmonic Force Field for the ${ }^{2} \mathrm{~B}_{1}$ Cation. J. Chem. Phys. 1985, 82, 5329-5339; (b) Leclaire, J. E.; Anand, R.; Johnson, P. M. Photoinduced Rydberg Ionization Spectroscopy of Phenol: The Structure and Assignment of the b-State of the Cation. J. Chem. Phys. 1997, 106, 6785-6794; (c) Ishiuchi, S. I.; Shitomi, H.; Takazawa, K.; Fujii, M. Nonresonant Ionization Detected IR Spectrum of Jet-cooled Phenol. Ionization Mechanism and Its Application to Overtone Spectroscopy. Chem. Phys. Lett. 1998, 283, 243-250; (d) Maquestiau, A.; Flammang, R.; Pauwels, P.; Vallet, P.; Meyrant, P. Tautomeric $\left[\mathrm{C}_{6} \mathrm{H}_{6} \mathrm{O}\right]^{+} \cdot$ Radical Cations. Org. Mass Spectrom. 1982, 17, 643; (e) Turecek, F.; Drinkwater, D. E.; Maquestiau, A.; McLafferty, F. W. Neutralization Reionization Study of $\mathrm{C}_{6} \mathrm{H}_{6} \mathrm{O}$ Isomers. Org. Mass Spectrom. 1989, 24, 669-672; (f) Borchers, F.; Levsen, K.; Theissling, C. B.; Nibbering, N. M. M. A Collisional Activation Study of $\left[\mathrm{C}_{6} \mathrm{H}_{6} \mathrm{O}^{{ }^{+}+}\right]$Ions Generated from the Molecular Ions of 2-Phenoxyethyl Halides. Org. Mass Spectrom. 1977, 12, 746-750; (g) van Velzen, P. N. T.; van der Hart, 
W. J.; van der Greef, J.; Nibbering, N. M. M.; Gross, M. L. Photodissociation Study of $\mathrm{C}_{6} \mathrm{H}_{6} \mathrm{O}^{-+}$Ions in an Ion Cyclotron Resonance Spectrometer. J. Am. Chem. Soc. 1982, 104, 1208-1212.

8. Le, H. T.; Flammang, R.; Gerbaux, P.; Bouchoux, G.; Nguyen, M. T. Ionized Phenol and Its Isomers in the Gas Phase. J. Phys. Chem. A 2001, 105, 11582-11592.

9. Muntean, F.; Armentrout, P. B. Modeling Kinetic Shifts for Tight Transition States in Threshold Collision-Induced Dissociations. J. Phys. Chem. B 2002, 106, 8117-8124.

10. (a) Bateman; R. H., Brown, J.; Lefevere, M.; Flammang, R.; Van Haverbeke, Y. Applications in Gaseous Ion and Neutral Chemistry Using a Six-Sector Mass Spectrometer. Int. I. Mass Spectrom. Ion Process 1992, 115 205-218; (b) Flammang, R.; Van Haverbeke, Y.; Braybrook, C.; Brown, J. A New Hybrid Mass Spectrometer for the Investigation of Ion/Molecule Reactions. Rapid Commun. Mass Spectrom. 1995, 9, 795-799.

11. Ramesh, V.; Reddy, P. N.; Bhanuprakash, K.; Srinivas, R.; Flammang, R.; Dechamps, N.; Gerbaux, P. $\mathrm{C}_{2} \mathrm{H}_{2} \mathrm{~S}$ Radical Cations: Application of Mass Spectrometry Methodologies. Int. J. Mass Spectrom. 2007, 263, 289-297.

12. (a) Gilman, J. P.; Hsieh, T.; Meisels, G. G. Competition between Isomerization and Fragmentation of Gaseous Ions. II. Nitromethane and Methyl Nitrite Ions. J. Chem. Phys. 1983, 78, 1174-1179; (b) Cimarusti, C. M.; Wolinsky, J. Synthesis and Bisdecarboxylation of Oxygenated Bicyclo[2.2.X]alkanedicarboxylic Anhydrides. J. Am. Chem. Soc.1968, 90, 113-120

13. Frisch, M. J., Trucks, G. W., Schlegel, H. B., Scuserai, G. E., Robb, M. A., Cheeseman, J. R., Zakrzewski, V. G., Montgomery, J. A., Stratmann, R. E., Burant, J. C., Dapprich, S., Millam, J. M., Daniels, A. D., Kudin, K. N., Strain, M. C., Farkas, O., Tomasi, J., Barone, V., Cossi, M., Cammi, R., Mennucci, B., Pomelli, C., Adamo, C., Clifford, S., Ochterski, J., Petersson, G. A., Ayala, P. Y., Cui, Q., Morokuma, K., Malick, D. K., Rabuck, A. D., Raghavachari, K., Foresman, J. B., Cioslowski, J., Ortiz, J. V., Stefanov, B. B., Liu, B. B., Liashenko, A, Piskorz, P., Komaromi, A. Gomperts, R., Martin, R. L., Fox, D. J., Keith, T., Al-Laham, M. A., Peng, C. Y., Nanayakkara, M. W., Gonzalez,, C., Challacombe, M., Gill, P. M. W., Johnson, B. G., Chen," W., Wong," M. W., Andres, J. L., Head-Gordon, M., Reploge, E. S., Pople, J. A. Gaussian 98, Gaussian, Inc.: Pittsburgh, PA, 1998.

14. See for instance: (a) Shay, B. J.; Eberlin, M. N.; Cooks, R. G.; Wesdemiotis, C. Ion-Molecule Reactions and Collision-Activated Dissociation of $\mathrm{C}_{4} \mathrm{H}_{4}{ }^{+}$Isomers: A Case Study in the Use of the MS ${ }^{3}$ Capabilities of a Pentaquadrupole Mass Spectrometer. I. Am. Soc. Mass Spectrom. 1992, 3 , 518-534; (b) Gerbaux, P.; Flammang, R.; Pedersen, C. Th.; Wong, M. W. Characterization of New Sulfide Ions $\left(\mathrm{C}_{2} \mathrm{~S}_{3}{ }^{+\bullet}\right)$ from Ethenedithione by Ion-Molecule Reactions. J. Phys. Chem. A 1999, 103, 3666-3671; (c) Gerbaux, P.; Barbieux-Flammang, M.; Terlouw, J. K.; Flammang, R. Definitive Characterization of Some $\mathrm{C}_{5} \mathrm{H}_{5} \mathrm{~N}^{\bullet+}$ and $\mathrm{C}_{6} \mathrm{H}_{7} \mathrm{~N}^{\bullet+}$ Radical Cations by Associative Ion-Molecule Reactions. Int. J. Mass Spectrom. 2001, 206, 91-103.

15. Polasek, M.; Turecek, F.; Gerbaux, P.; Flammang, R. Nitrobenzene Isomers. J. Phys. Chem. A 2001, 105, 995-1010.

16. Schwartz, J. C.; Wade, A. P.; Enke, C. G.; Cooks, R. G. Systematic Delineation of Scan Modes in Multidimensional Mass Spectrometry. Anal. Chem. 1990, 62, 1809-1818.
17. van der Rest, G.; Chamot-Rooke, J.; Mourgues, P.; McMahon, T. B.; Audier, H. E. Ter-Body Intermediates in the Gas Phase: Reaction of Ionized Enols with tert-Butanol. J. Am. Soc. Mass Spectrom. 2001, 12, 938-947.

18. Hammerum, S. Distonic Radical Cations in Gaseous and Condensed Phase. Mass Spectrom. Rev. 1988, 7, 123-202.

19. Tomazela, D. M.; Sabino, A. A.; Sparrapan, R.; Gozzo, F. C.; Eberlin, M. N. Distonoid Ions. J. Am. Soc. Mass Spectrom. 2006, 17, 1014-1022.

20. McKnee, M. L.; Mayer, P. M.; Radom, L. An Ab Initio Study of Ionised Cyclobutanone and Cyclopentanone. Comparison of the Thermodynamic and Kinetic Stabilities of the Distonic Isomers ${ }^{-} \mathrm{CH}_{2}\left(\mathrm{CH}_{2}\right)_{\mathrm{n}}{ }^{+} \mathrm{C}=\mathrm{O}$. Eur. Mass Spectrom. 1998, 4, 23-30; and references cited therein

21. Stirk, K. M.; Smith, R. L.; Orlowski, J. C.; Kenttämaa, H. I. Bimolecular Reactions Involving the Radical Site of the Distonic Ion - $\mathrm{CH}_{2} \mathrm{CH}_{2} \mathrm{CH}_{2} \mathrm{CH}_{2}{ }^{+} \mathrm{C}=\mathrm{O}$. Rapid Commun. Mass Spectrom. 1993, 7, 392 399.

22. George, L.; Veedu, R. N.; Sheibani, H.; Taherpour, A. A.; Flammang, R. Wentrup, C. Carboxyketenes from 4-Hydroxy-1,3-oxazin-6-ones and Meldrums' Acid Derivatives. J. Org. Chem. 2007, 72, 1399-1404.

23. Brown, J.; Flammang, R.; Govaert, Y.; Plisnier, M.; Wentrup, C.; Van Haverbeke, Y. Electron-Impact and Chemical Ionization Mass Spectrometry of Heterocumulenes Produced by Flash Vacuum Pyrolysis. Rapid Commun. Mass Spectrom. 1992, 6, 249-253.

24. (a) (a) Bohme, D. K. Proton Transport in the Catalyzed Gas-Phase Isomerization of Protonated Molecules. Int. J. Mass Spectrom. Ion Process 1992, 115, 95-110; (b) Haranczyk, M.; Burgers, P. C.; Ruttink, P. J. A. Catalysis Models for the Enolization of the Acetaldehyde Radical Cation. Int. J. Mass Spectrom. 2002, 220, 53-67.

25. van der Rest, G.; Nedev, H.; Chamot-Rooke, J.; Mourgues, P.; McMahon, T. B.; Audier, H. E. Proton-Transport Catalysis in the Gas Phase. Keto-Enol Isomerization of Ionized Acetaldehyde. Int. J. Mass Spectrom. 2000, 202, 161-174.

26. (a) Trikoupis, M. A.; Terlouw, J. K. Enolization of Gaseous Acetone Radical Cations: Catalysis by a Single Base Molecule. J. Am. Chem. Soc. 1998, 120, 12131-12132; (b) Trikoupis, M. A.; Burgers, P. C.; Ruttink, P. J. A.; Terlouw, J. K. Self-Catalysis in the Gas-Phase: Enolization of the Acetone Radical Cation. Int. J. Mass Spectrom. 2002, 217, 97-108.

27. Chamot-Rooke, J.; van der Rest, G.; Mourgues, P.; Audier, H. E. Two Different Pathways for Unimolecular and for Catalyzed Keto-Enol Isomerization of Ionized Acetophenone. Int. J. Mass Spectrom. 2000, 195/196, 385-392.

28. (a) Mourgues, P.; Chamot-Rooke, J.; Nedev, H.; Audier, H. E. Spontaneous and Catalyzed Isomerizations of the Acetamide Radical Cations. J. Mass Spectrom. 2001, 36, 102-104; (b) Trikoupis, M. A.; Burgers, P. C.; Ruttink, P. J. A.; Terlouw, J. K. Benzonitrile Assisted Enolization of the Acetone and Acetamide Radical Cations: Proton-Transport Catalysis versus an Intermolecular $\mathrm{H}^{+/} \bullet$ Transfer Mechanism. Int. J. Mass Spectrom. 2001, 210/211, 489-501.

29. Chalk, A. J.; Radom, L. Ion-Transport Catalysis: Catalyzed Isomerizations of $\mathrm{NNH}^{+}$and $\mathrm{NNCH}_{3}{ }^{+}$. J. Am. Chem. Soc. 1999, 121, 1574-1581. 